\title{
New Silica Coating Pigment for Inkjet Papers from Mining Industry Sidestreams
}

\author{
Taina Lamminmäki, Eija Kenttä, Hille Rautkoski, John Bachér, Sebastian Teir, \\ John Kettle, Juha Sarlin
}

VTT Technical Research Centre of Finland, Espoo, Finland.

Email: firstname.lastname@vtt.fi

Received April 25 $5^{\text {th }}, 2013$; revised May 26 ${ }^{\text {th }}, 2013$; accepted June $15^{\text {th }}, 2013$

Copyright (C) 2013 Taina Lamminmäki et al. This is an open access article distributed under the Creative Commons Attribution License, which permits unrestricted use, distribution, and reproduction in any medium, provided the original work is properly cited.

\begin{abstract}
Silica is commonly used as an ingredient in the coatings of inkjet papers because of its capability to provide a coating layer structure combining a high pore volume, into which all the applied inkjet ink can transfer, and a suitable pore size distribution for very quick ink absorption. Nowadays, the production of silica pigment is quite expensive, and therefore, it would be advantageous to find a cheaper raw material source. In this study, the raw material was Greek olivine from magnesite mine sidestreams. The silica pigment was produced at laboratory scale by using nitric acid as a solvent. The target of this work was to clarify how this produced silica pigment is suited for inkjet coating pigments. The coating colors were applied by a laboratory rod coater on fine base paper and white-top kraftliner, and the coated surfaces were printed with a home and office area inkjet printer. The results showed that the produced olivine-based silica pigment has a potential in matt inkjet coatings. The coating of the produced silica pigment increased the print density, decreased the print-through, and diminished the bleeding of fine paper and white-top kraftliner board. However, further development work is needed to improve the pigment brightness to a more acceptable level, and to control the particle size at the nitric acid dissolution.
\end{abstract}

Keywords: Silica; Coating Pigment; Inkjet Printing; Print Quality; Ink Penetration; Ionic Charge; Dye Transfer Process

\section{Introduction}

Inkjet printing has penetrated into the printing industry, and research into special coatings for inkjet application has consequently been quite abundant. Firstly, the applied water-based inkjet ink should absorb rapidly into the coated paper structure, so that the different color inks have as short a time as possible to mix together. Secondly, the paper structure should have adequate pore volume into which all the applied ink can transfer. The third challenge for the surfaces is the direction in which the ink can transfer. There is always some ink spreading on the surface, but this should be under control. The surface direction $(\mathrm{x}, \mathrm{y})$ spreading should be minimal, the main direction being in the coating ( $\mathrm{z}$ ) direction. All these properties affect the print quality formation - print density, color tone, print-through, mottling and bleeding. Besides the ink penetration, there is the fixing of the ink colorant molecules. The colorant should have enough time to fix to the coating layer so that from the optical point of view it settles at the most effective location.
Binding of the ink colorant to the surface so permanent that it cannot escape from the surface by touching or rubbing would also be advantageous.

Silica pigments have been shown to be very useful pigments in inkjet coatings [1-6]. The high specific surface area of the silica pigment produces a coating layer with high pore volume and optimal pore size distribution for fast ink penetration. The pigment particles can have internal pores, i.e., the pigment particles themselves have very small pores. This kind of pigment structure produces a dual-pore size distribution of coating layer, so that different absorption phenomena, capillary and permeation flow can occur during the imbibition of inkjet ink. The target of ink penetration is to transfer most of the ink in the thickness direction of the paper and to restrict transfer in the $\mathrm{x}, \mathrm{y}$ direction. The hydrophilic nature of silica pigment further promotes the absorption of the silica coating [7]. One factor limiting the wider use of silica pigments is the low solids content $(<30 \%)$ of silica coating formulas [7], which limits the coating speed of the color, for example. Another restrictive factor is that 
the high specific surface area of silica pigment requires a high amount of binder to fix the coating color to the paper surface, and this further increases the cost of the coating layer. As well as the silica pigments, other pigments have been developed for the coatings of inkjet printing, such as precipitated and modified calcium carbonates $[1,6,8]$.

One of the most effective binders, polyvinyl alcohol $(\mathrm{PVOH})$, can provide acceptable binding strength for the high specific surface area pigments containing coating layers, and is therefore the most common binder in inkjet coatings. The polymer chain of PVOH contains both acetate and hydroxyl pendant groups, which form a partially crystalline polymer structure. The degree of crystallization is adjusted by the amount of acetate groups. At a certain moisture content, low hydrolyzed grade $\mathrm{PVOH}$ swells more than high hydrolyzed grade because it has more amorphous regions in which water molecules can bind [9]. The dye-based colorant of inkjet ink can follow a water-based ink vehicle into the hydrophilic binder matrix and stay there after ink drying [10]. High hydrolyzed $\mathrm{PVOH}$ instead provides better binding strength than low hydrolyzed PVOH $[9,11]$ for the porous coating structure. The increase of polymerization further improves the binding power of $\mathrm{PVOH}$ [9]. Besides $\mathrm{PVOH}$, the use of coating pigments other than silicas has introduced some other binders in inkjet coatings, such as polyvinyl pyrrolidone, vinyl acetate and starch $[8,10,12]$.

Amorphous silicas are usually classified as colloidal, fumed, or precipitated silica and silica gel $[6,13]$. Colloidal silica particles do not have intraparticle pores, and the particle diameter of the pigment varies from $10 \mathrm{~nm}$ to $200 \mathrm{~nm}$. The fumed silica has clearly smaller pigment particle diameters $(10-20 \mathrm{~nm})$, but the small particles normally form agglomerates $(100-300 \mathrm{~nm})$. The individual pigment particle does not have pores. With a high temperature hydrolysis process, for example, hydrophilic fumed silica, amorphous silicon dioxide, with very small size pigment particles can be produced [14]. This process enables the production of dry pigments within the diameter range of $7-40 \mathrm{~nm}$ and the specific surface area of $50-300 \mathrm{~m}^{2} \cdot \mathrm{g}^{-1}$. The silica gel is a hydrogel network of non-porous structures (micelles) with siloxane bonds. The dried gel forms a high porosity by producing a sponge-like structure. Precipitated silica has intraparticle pores, and the sponge-like structure forms a high specific surface area of $50-700 \mathrm{~m}^{2} \cdot \mathrm{g}^{-1}$ [15], and the final produced coating layer has a high pore volume. Nano-size silica pigments are widely used due to their capability to increase the gloss of the coating layer [16].

The silica in this work was produced from olivine (magnesium and iron silicate). Olivine is a very common mineral that has been considered as promising for $\mathrm{CO}_{2}$ storage by mineralization, but so far all such processes have required too much energy to be feasible. Olivine, $(\mathrm{Mg}, \mathrm{Fe})_{2} \cdot \mathrm{SiO}_{4}$, forms a mineral series in which the ratio of magnesium to iron varies. The iron free $\mathrm{Mg}_{2} \mathrm{SiO}_{4}$ is called Forsterite, and the magnesium-free $\mathrm{Fe}_{2} \mathrm{SiO}_{4}$ Fayalite [17]. Olivine is water-free and has orthorhombic crystal structure with a specific gravity of $3.2 \mathrm{~g} \cdot \mathrm{cm}^{3}$ (increasing to $4.3 \mathrm{~g} \cdot \mathrm{cm}^{3}$ as iron content increases), index of refraction $1.64-1.70$ and hardness 6.5 - 7.0 [18].

The target of this work was to clarify how the produced silica pigment obtained from Greek olivine is suited for the coating pigments of matt inkjet papers. The other target was to define how the silica coatings work on the uncoated board surface. The produced silica is compared to commercial silica coating pigments. In our case, the olivine produced at the mine has no use, and therefore it would be advantageous, if an expensive silica pigment can be produced from this cheap raw material. Nitric acid was used as a solvent in the production of silica pigments from olivine. The pigment coatings were applied on commercial fine paper and uncoated board surface, after which the papers were printed with a desktop inkjet printer, and the print quality was analyzed. In addition, we studied how the addition of calcium carbonate affects the properties of silica containing coatings.

\section{Materials and Methods}

The silica pigment was produced by VTT from olivine rock, supplied from the Yerakini magnesite mine. The chemical used was nitric acid. The olivine raw material was composed of two different size fractions, 250 - 355 $\mu \mathrm{m}$ and $>355 \mu \mathrm{m}$, the relative portions of which were $60 \%$ and $40 \%$ respectively. The raw material had been pretreated in Greece with magnetic separation to reduce the iron content of the material. Silica production at VTT used a batch reactor with $2000 \mathrm{ml}$ of $4 \mathrm{M} \mathrm{HNO}_{3}$ and heated to $75^{\circ} \mathrm{C}$. The reactor was sealed to prevent escape of nitric acid vapors. After the temperature had stabilized, $280 \mathrm{~g}$ of olivine was added to the reactor. The slurry was mixed using a mechanical stirrer (around $500 \mathrm{rpm}$ ). After $4 \mathrm{~h}$ the slurry was allowed to settle in a beaker for a few minutes, after which it was decanted and pipetted to a pressure filter. The coarser unreacted olivine residual remained in the bottom of the beaker, while the reacted silica gel/slurry entered filtration. The filtration was performed under 4 bar pressure with a filter paper that had a porosity of $0.7-5 \mu \mathrm{m}$. To remove any residual acid the filtered silica was washed using several passes with deionized water. The filtered silica solids were then dried at $105^{\circ} \mathrm{C}$. The dried silica was ground with a ball mill and mortar mill for $3 \mathrm{~h}$ and $10 \mathrm{~min}$, respectively, after which the ground silica was treated with an ultrasonic bath for $15 \mathrm{~min}$. The final slurry for coating experiments had a solid content of $37 \%$.

The produced silicas were compared to a commercial 
colloidal nanosilica (Bindzil 50/80, provided by Eka Chemicals AB), fumed (Aerosil MOX 170, from Evonik Industries $A G$ ), and a precipitated silica pigment (Sipernat 310, provided by Evonik Industries AG). The measured properties of the studied silica pigments have been introduced in Table 1. The precipitated silica pigment particles had intraparticle pores, meaning that there are very small pores in the individual particles. The precipitated silica consisted solely of silicon dioxide $\left(\mathrm{SiO}_{2}\right)$, while the pigment produced at VTT contained $94 \mathrm{wt} \%$ of silica. The main impurity in the produced silica was iron $(0.16 \mathrm{wt} \%)$ [19]. Although the target was to produce particle sizes in the nanoscale range, the produced silica had particle sizes in the micrometer range. All pigments produced anionic pigment slurry in water.

Ground calcium carbonate (Hydrocarb 90 from Omya AG) was also used in some coating formulations (mean particle diameter was $700 \mathrm{~nm}$, specific surface area 12 $\mathrm{m}^{2} \cdot \mathrm{g}^{-1}$ ). The idea was to clarify whether it is possible to decrease the amount of silica pigment used in the coating color in order to achieve a less expensive coating layer, without deteriorating the properties of the coating layer too much. In the case of using the fumed silica, the $\mathrm{pH}$ of silica pigments had to be adjusted to the neutral area before mixing it with the ground $\mathrm{CaCO}_{3}$ in order to avoid the breaking of the carbonate pigment. The binder was polyvinyl alcohol, PVOH (Mowiol 40 - 88 provided by Kuraray Specialities Europe $\mathrm{GmbH}$, which had a $87.7 \pm$ $1.0 \%$ degree of hydrolysis, and a molecular weight of 204,000 $\left.\mathrm{g} \cdot \mathrm{mol}^{-1}[20]\right) .0 .4 \mathrm{pph}$ cationic poly(diallyl dimethyl ammonium chloride) (polyDADMAC, Cartafix VXL) was added to the coating colors. The recipes of coating colors are shown in Table 2. In the result part, each coating layer is named after the main silica pigment in the recipe.

The coating colors were applied on a commercial fine paper base $\left(80 \mathrm{~g} \cdot \mathrm{m}^{-2}\right)$ and on a commercial uncoated board (white-top kraftliner, $320 \mathrm{~g} \cdot \mathrm{m}^{-2}$ ) using an Erichsen film applicator (Model 288). The target for the coat weight was $10 \mathrm{~g} \cdot \mathrm{m}^{-2}$. The coatings were dried for $5 \mathrm{~min}-$ utes inside an oven at $105^{\circ} \mathrm{C}$ temperature. The coated surfaces were uncalendered. The precipitated silica containing coating color represented a generally known, good inkjet print quality producing coating color.

Table 1. Properties of studied silica pigments.

\begin{tabular}{|c|c|c|c|c|c|}
\hline Pigments & Slurry/powder & Mean particle diameter, $\mathrm{nm}$ & $\begin{array}{l}\text { Specific surface area, } \\
\text { BET, } \mathrm{m}^{2} \cdot \mathrm{g}^{-1}\end{array}$ & $\mathrm{pH}$ & $\begin{array}{l}\text { Zeta potential (in water } \\
\text { solution), } \mathrm{mV}^{* * * *}\end{array}$ \\
\hline $\begin{array}{l}\text { Colloidal nanosilica, } \\
\text { Bindzil 50/80 }\end{array}$ & Slurry, solids content of $52 \%$ & $20-100^{* *}$ & $80^{* *}$ & 9.5 & -55 \\
\hline $\begin{array}{l}\text { Fumed nanosilica, } \\
\text { Aerosil MOX } 170\end{array}$ & Powder & $30^{* *}$ & $170 \pm 30^{* *}$ & $3.6-4.5$ & -49 \\
\hline $\begin{array}{l}\text { Precipitated silica, } \\
\text { Sipernat } 310\end{array}$ & Powder & $5000^{* *}$ & $750^{* *}$ & 6 & -36 \\
\hline Produced silica & Slurry, solids content of $37 \%$ & $9900^{*}$ & $160^{* * *}$ & 5.8 & -38 \\
\hline
\end{tabular}

${ }^{*}$ Measured with Beckham Coulter LS 230. ${ }^{* *}$ Measured by pigment suppliers. ${ }^{* * *}$ Measured with TriStar $3000 .{ }^{* * * *}$ Measured with AcoustoSizer II.

Table 2. The produced coating color recipes and their properties.

\begin{tabular}{|c|c|c|c|c|}
\hline & Colloidal nanosilica & Fumed nanosilica & Precipitated silica & Produced silica \\
\hline Ground calcium carbonate & 20 & 20 & & \\
\hline Colloidal silica & 80 & & & \\
\hline Precipitated silica & & & 80 & \\
\hline Fumed silica & & 80 & 20 & 20 \\
\hline Produced silica & & & & 80 \\
\hline $\mathrm{PVOH}$ & 25 & 25 & 25 & 25 \\
\hline \multicolumn{5}{|l|}{ Property of coating color } \\
\hline Solids content, $\%$ & 29.0 & 23.1 & 19.7 & 19.2 \\
\hline $\mathrm{pH}$ & 8.5 & 6.4 & 5.7 & 5.2 \\
\hline $\begin{array}{c}\text { Viscosity (Brookfield), } \mathrm{m} \cdot \text { Pas, } \\
100 / 50 \mathrm{rpm}\end{array}$ & $1840 / 2135$ & $3400 / 4680$ & $2725 / 5050$ & $725 / 930$ \\
\hline Zeta potential, $\mathrm{mV}$ & -4 & 38 & -8 & -4 \\
\hline
\end{tabular}


The coated surfaces were analyzed using air permeance, ISO-brightness, gloss $\left(75^{\circ}\right)$, roughness (Bendtsen and Parker Print-Surf), absorption time (DIGAT) and absorption speed (nozzle application) measurements. The air permeance was measured using an Air Permeance Tester (20 $\mathrm{kPa}$, based on Bendtsen method) following the ISO 5636-3 standard. ISO-brightness was measured according the standard ISO 2470-1:2009. The gloss of unprinted and printed surfaces was analyzed with a Zehntner-gloss meter by using the measuring angle of $75^{\circ}$ from normal direction. The roughness was measured with Bendtsen (measuring pressure $1.47 \mathrm{kPa}$ ) and Parker Print-Surf measurement $(10 \mathrm{kPa})$ by following standard ISO 8791-2:1990 and ISO 8791-4:2007, respectively. The pore diameters of coating layer surfaces were qualitatively estimated from scanning electronic microscope (SEM) images. The contact angles of water on the surfaces were measured with a tensiometer KSV CAM 200 device, as the apparent contact angle was detected after $0.5 \mathrm{~s}$.

The absorption time of ink was measured with a DIGAT device (Dynamic Ink Gloss and Absorption Tester) [21]. DIGAT measures the absorption time by detecting changes in the gloss level as the surface liquid transfers into the porous structure. The measurement starts from the moment when the ink arrives at the surface, and lasts until the gloss caused by the ink has reached an equilibrium value. Ink is applied on the surface with a glass capillary tube, using the ejector principle, and the ink forms a uniform layer on the paper surface. The light source is a laser (wave length $633 \mathrm{~nm}$ ). The detector part in the DIGAT measures the voltage from the gloss meter as a function of time. The laser beam and the detector are both fixed at an angle of $20^{\circ}$ to the horizontal surface. The result is given as absorption time corresponding to the time between $90 \%$ of the maximum gloss value and $10 \%$ of the equilibrium liquid saturation gloss value. The applied ink was an anionic aqueous dye-based ink from a Versamark VX5000e, and the ink amount was about 8 $\mathrm{g} \cdot \mathrm{m}^{-2}$.

The other device used for analyzing the surface absorption properties of inkjet ink was a nozzle application, which is otherwise very similar to the "Bristow wheel" [22], but in this case the nozzle transferred on the planar surface. In this measurement, the absorbed ink amount depends on the surface roughness volume, and on the absorption on the top layer as well as the absorption of the whole sample. The inkjet ink was applied on the surface with a $1.2 \mathrm{~mm}$ width nozzle slit using different nozzle speeds. The liquid amount transferred into the paper structure was measured with a microbalance unit. The final absorbed ink amount was determined at the time of $8 \mathrm{~ms}$.

The printing was performed by an HP Deskjet 2050 inkjet printer using the following printing preferences: plain paper and normal quality. The printer had an aqueous pigment-based black ink and the other inks were aqueous dye-based inks. The target of the printing was to determine the differences between the silica coatings studied, and therefore, more detailed print quality aspects were not identified. The print density was measured with a spectrophotometer (GretagMacbeth D196) and the print-through with an Elrepho Spectrophotometer (following the standard ISO 5631-1:2009) by measuring through the paper, which had a $100 \%$ tint area on the reverse side. The ink bleeding in respect to line width and raggedness was analyzed with a QEA personal IAS system following the standard ISO 13660:2001. The figures of the printed surfaces were scanned by HP Deskjet 2050 J150 scanner.

\section{Results and Discussion}

\subsection{The Properties of Coated Surfaces}

Figure 1 shows the coat weights of the coated surfaces. On the board surface the colloidal silica coating had the highest coat weight with the highest standard deviation indicating the non-uniformity of the coating layer.

The applied silica coatings on the paper or board surfaces increased the ISO brightness, as Figure 2 illustrates. The produced silica on the fine paper surface made the only exception. The iron impurity in this silica is the likely reason for lowering of brightness. On the board surface, which had clearly lower ISO brightness than the fine paper, the light brown color of produced silica did not further decrease the ISO brightness of coated board. The board containing produced silica had the same ISO brightness as that containing fumed silica.

The results of air permeance are shown in Figure 3(a). The colloidal nanosilica containing structure with calcium carbonate pigment effectively closes the fine paper surface, and therefore air permeance was low. At the same time, this coated paper structure absorbed less ink-

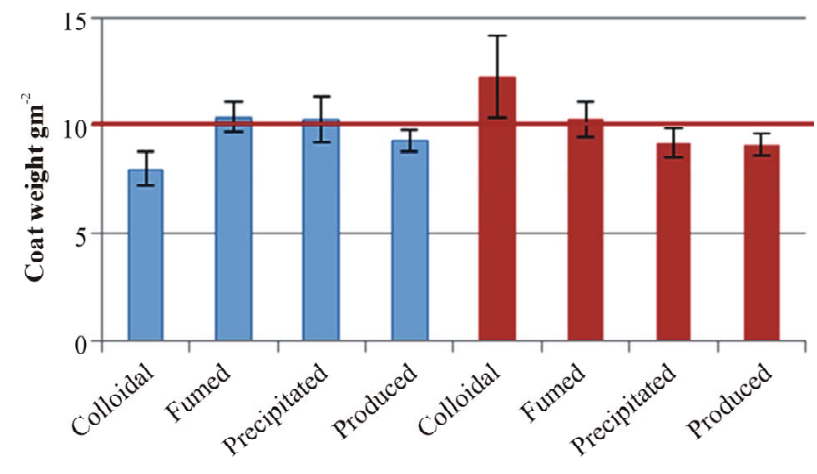

Fine paper Board

Figure 1. Coat weight of the studied fine papers and boards. The target for the coat weight was $10 \mathrm{~g} \cdot \mathrm{m}^{-2}$. 


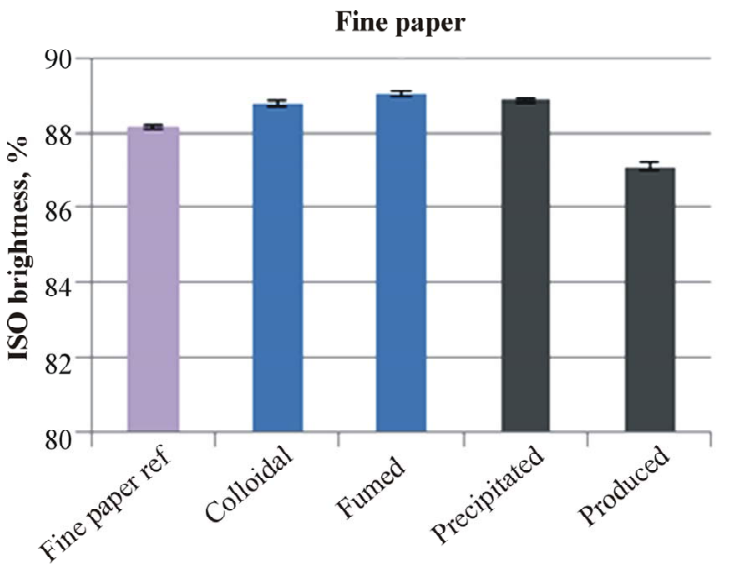

(a)

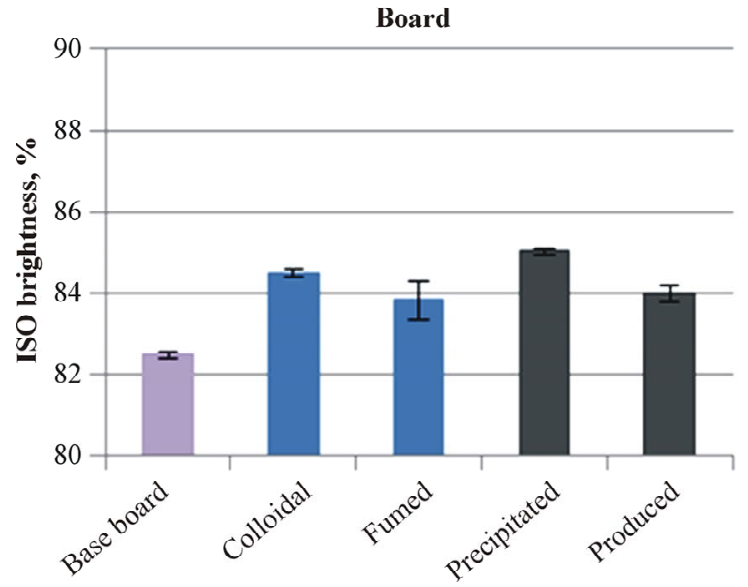

(b)

Figure 2. The brightness of uncoated and silica coated fine papers (a) and boards (b).

jet ink (Figure 3(b)) and the absorption time of dyebased inkjet ink increased up to $1.5 \mathrm{~s} \mathrm{(Figure} \mathrm{3(c)).} \mathrm{The}$ fumed silica coating had the longest absorption time.

All coating layers had hydrophilic surfaces except fumed silica. The contact angle of water on the surface containing fumed silica was $98.6^{\circ}$ whereas on the colloidal silica coating it was $78.5^{\circ}$. The wetting of a hydrophobic coating layer requires more time before the inkjet ink penetration can start. Tiberg et al. [23] showed that in the case of internally hydrophobic capillaries, the hydrophobicity prevents the polar liquid penetration at the beginning of ink imbibition. After a while, the penetration starts as surfactants permit surface wetting.

The silica coatings without calcium carbonate pigment (precipitated and produced) produced a coating layer structure with higher air permeance, a higher inkjet ink absorption amount at $8 \mathrm{~ms}$ and quicker absorption time of inkjet ink than calcium carbonate containing coatings (colloidal and fumed silica). The results indicate that these coating structures have higher porosity.

The lowest Parker Print-Surf roughness result was at-

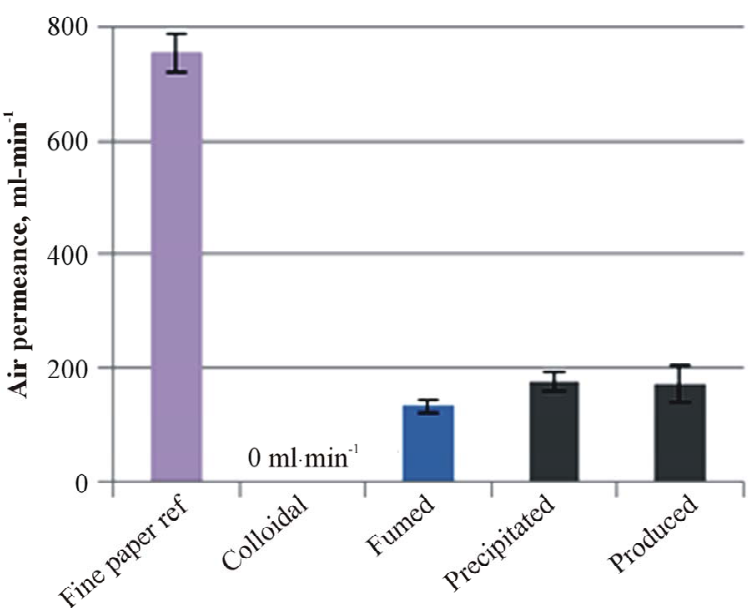

(a)

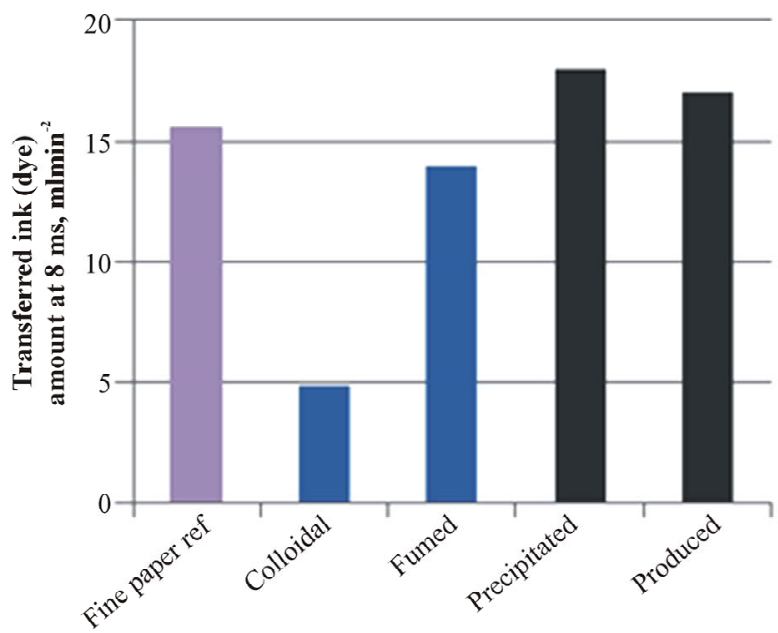

(b)

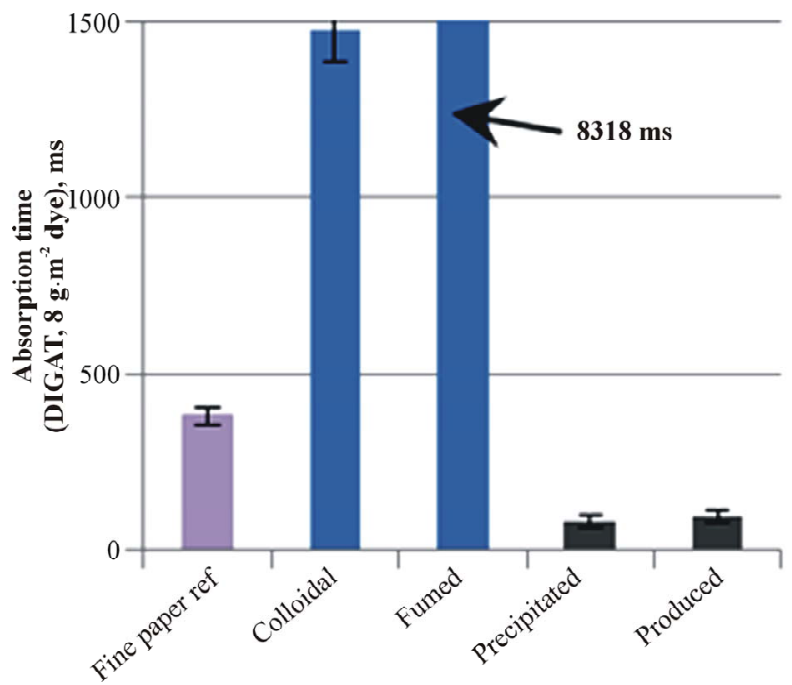

(c)

Figure 3. The air permeance (a), the absorbed inkjet ink amount at $8 \mathrm{~ms}$ (b) and the absorption speed of inkjet ink (c) on the fine paper and coated fine papers containing silica pigment. 
tained with the coatings of colloidal and precipitated silica, and the highest with the fumed or produced silica (Figure 4(a)). When the roughness measuring pressure decreased, as in the Bendtsen device, the coating containing fumed silica provided the highest roughness. Otherwise, these results were very similar to the results of Parker Print-Surf. The produced silica had the largest pigment particle diameter, which can explain the high roughness values. Interestingly, the highest gloss was reached with the coating containing fumed silica (Figure 4(b)). The colloidal and fumed silica had the smallest size pigment particles, and were therefore expected to produce a more packed coating layer structure with the calcium carbonate pigment.

Figure 5 shows the scanning electron microscopy images of silica coatings on the fine paper surface. We can see from the images that all the coatings had completely covered the paper fibers. The fumed silica coating exhibits cracks, which are very common in the case of inkjet coatings $[2,4,5]$. The size of cracks is in the order of mi-

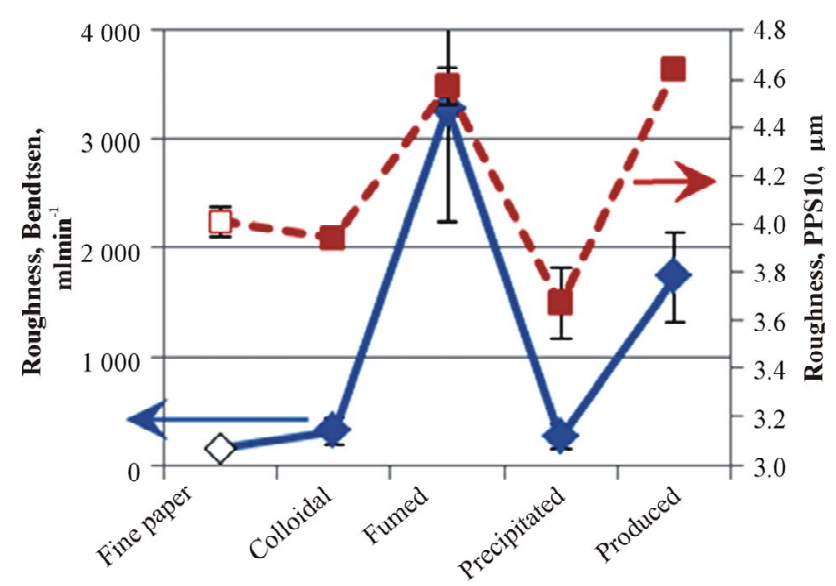

(a)

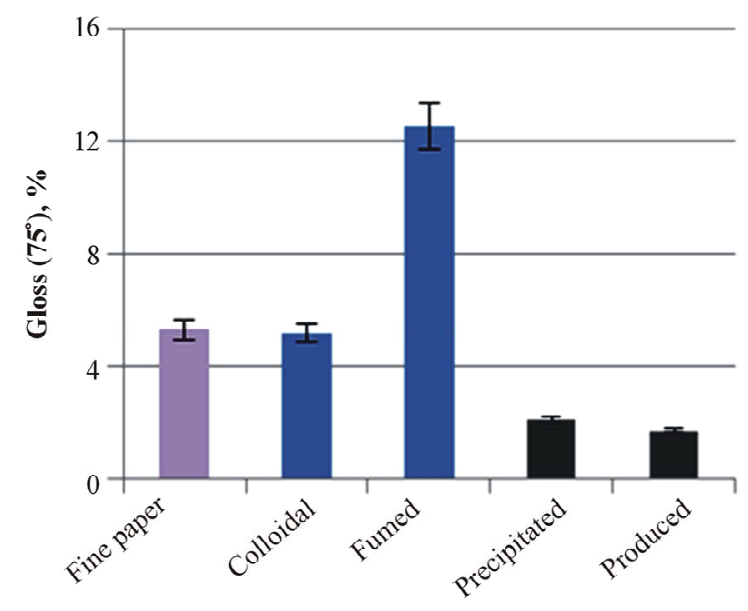

(b)

Figure 4. The roughness (Bendtsen and Parker Print-Surf, (a) and gloss (b) of fine paper and coated fine papers containing silica.

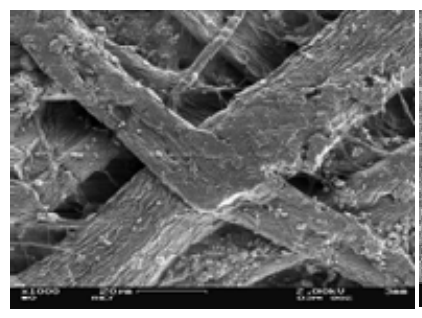

Fine paper, uncoated

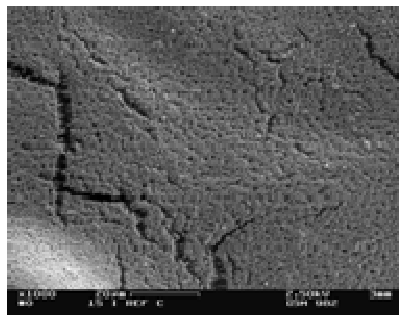

Fumed nanosilica

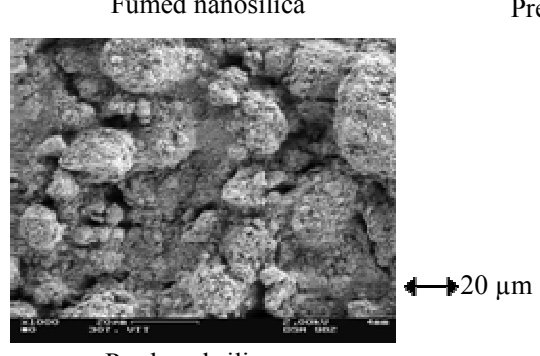

Produced silica

Figure 5. Scanning electron microscopy image (SEM) of coatings containing silica pigment on the fine paper surface. Magnification of 1000. Colloidal and fumed silica coating colors contained $20 \mathrm{pph} \mathrm{CaCO}_{3}$ pigment.

crometers. The cracks can be the result of shrinkage occurring through the low solids content of coating colors and the use of soluble binders that fail to resist shrinkage [24]. The smaller the particle size of silica, the greater the forces of surface tension in the drying process of the coating layer, and this can develop cracks in the coating layer [5]. On the other hand, the fumed silica consists of very smooth areas between the cracks, which in this research results in a few percentage units higher gloss than the other silica surfaces studied. The cracks can explain the high air permeance results of the paper containing fumed pigment. The coating layer structures of the laboratory-produced silica pigment and the precipitated silica look alike, although the produced silica containing coating seems to have some larger size clusters/particles covered with small size particles; the produce silica had 9.9 $\mu \mathrm{m}$ diameter pigment particles. Both coating surfaces seem to have pores with diameters in the order of micrometers.

Figure 6 shows the same coated surfaces at higher magnification than in Figure 5. All coating layers have $100 \mathrm{~nm}$ diameter pores, but with most pores $10-20 \mathrm{~nm}$ in diameter. The surface of coating containing colloidal nanosilica seems to have fewer pores below $20 \mathrm{~nm}$ di- 


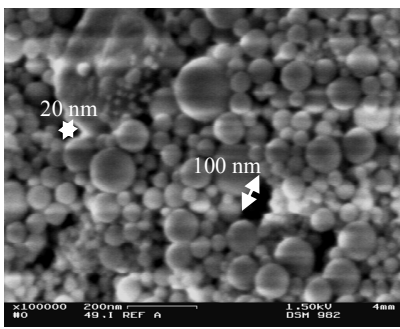

Colloidal nanosilica

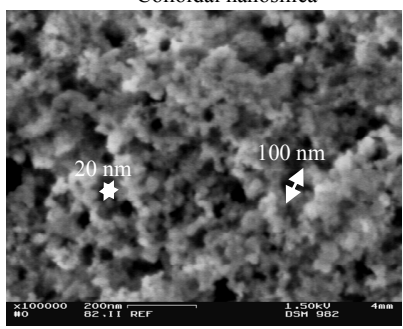

Precipitated silica

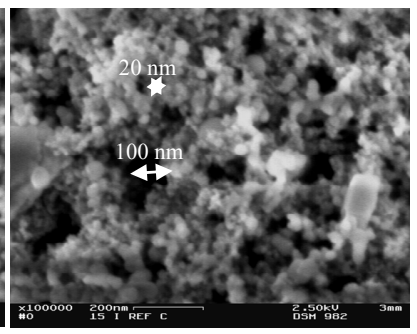
Fumed nanosilica

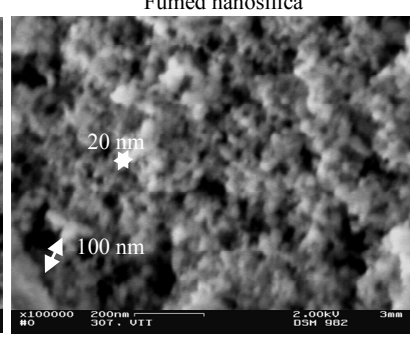

Produced silica
Figure 6. SEM image of coatings containing silica pigment on the fine paper surface. Magnification of 100,000 .

ameter than the other coatings, and the precipitated and produced silica coatings have again very similar structures.

\subsection{The Inkjet Print Quality}

Generally, the print densities of silica-coated surfaces were at a good level (Figure 7). Moreover, all silica coatings had higher print densities than untreated base paper or board. At the same time, the results of the printthrough of the fine papers containing silica were lower than untreated base paper (Figure 8(a)), indicating that the inkjet ink colorant remains in the coating layer. Both coated base materials produced very similar result values, as print density results show in Figure 7.

As the coatings (colloidal and fumed silica) containing 20 pph $\mathrm{CaCO}_{3}$ are compared, we can see that the print density decreased as the air permeance and the absorbed ink amount of the coated surface increased. In the case of dye-based inkjet inks, the results of these coatings remained at a lower level than the results of coating containing precipitated silica, indicating that the coating structures have neither enough chemical groups nor places where the colorant can attach.

Comparing the print density results of pigment-based black ink on the coatings containing produced and precipitated silica, we discover that the results were very similar. However, the situation changed when dye-based ink was used. With dye-based ink, the surfaces containing produced silica had lower values than those containing precipitated silica. The air permeance, inkjet ink absorption time, transferred ink amount and glosses of these two coating layers were very similar, but the surface containing produced silica provided lower ISO

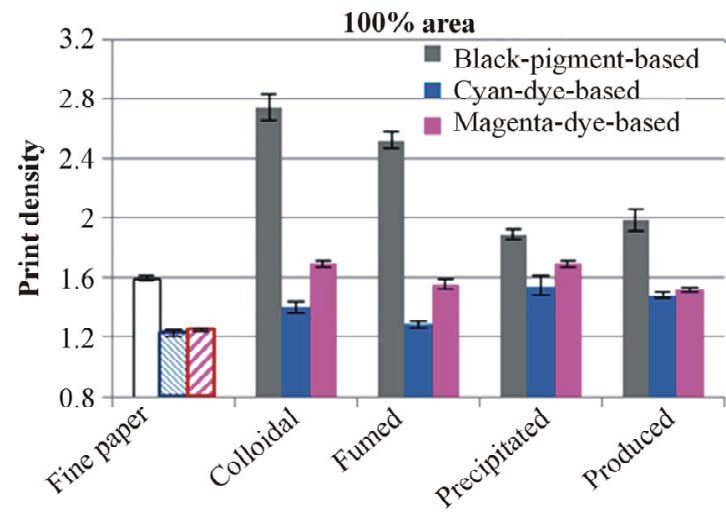

(a)

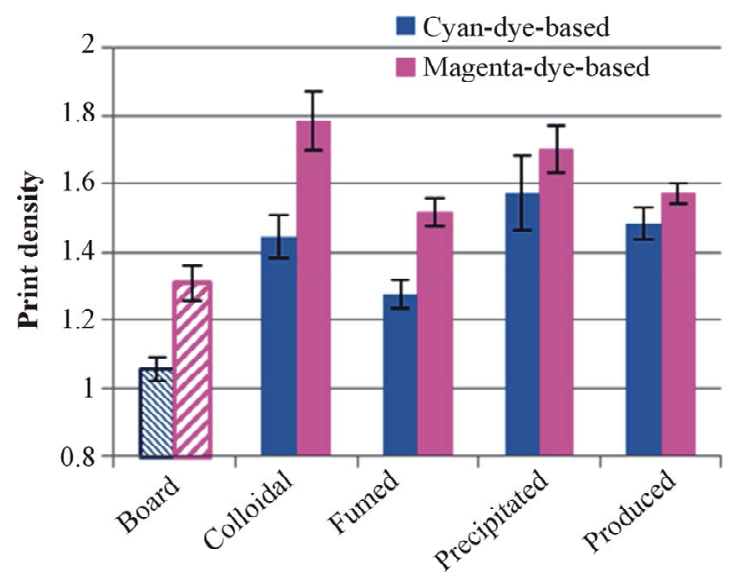

(b)

Figure 7. Results of the print density measurements of printed (100\% tint) fine papers (a) and boards (b). The printing was performed with an HP Deskjet 2050 printer.

brightness, which can be one reason for the lower print density of dye-based inkjet prints. On the other hand, the paper containing produced silica had higher printthrough than the paper coated with the precipitated silica pigment (Figure 8(a)). The ink colorant has transferred into the structures differently. The coating containing produced silica has not fixed colorant molecules as effectively as that containing precipitated silica; the structure of the coatings containing produced silica therefore requires further development work in order to get the colorant on the more effective part of the coating layer from the optical point of view.

As the print density results of dye-based inks are further compared to the results of pigment-based inks, it can be seen that the pigment-based black ink had clearly higher values than dye-based cyan and magenta. The colorant pigment forms a straightforward filter cake on the top of coating layers. The highest print densities with the black ink had developed on the most closed surfaces: the colloidal and fumed silica coatings. The ink pigment cake formation reflects further in the print gloss results. The paper containing colloidal silica had a print gloss of 


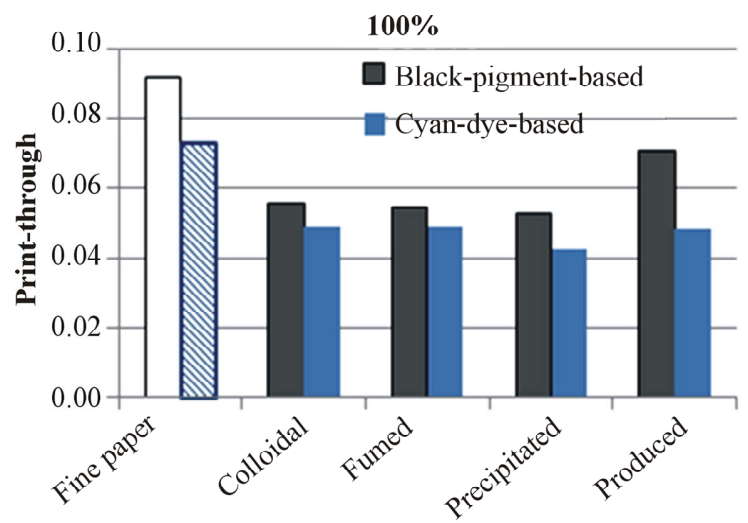

(a)

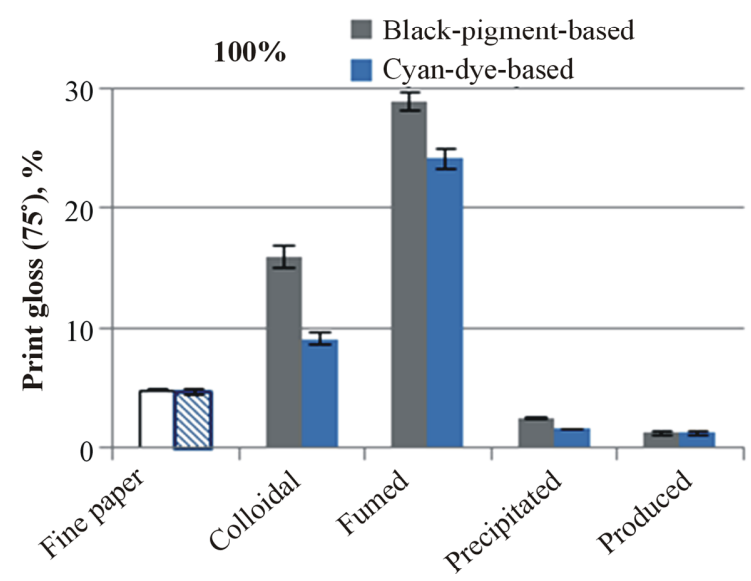

(b)

Figure 8. The print-through (a) and print gloss (b) of uncoated and silica-pigment-coated fine papers. The surfaces were printed with an HP Deskjet 2050.

$16 \%$ (Figure 8(b)), and the highest print gloss, 28\%, developed on the coating containing fumed silica. The coatings with precipitated and produced silicas had even lower print gloss than the printed base paper. Similarly, in the case of dye-based inkjet ink, the coatings containing colloidal and fumed silica had higher print gloss than the coating containing precipitated or produced silica.

Figure 9 illustrates some examples of the coatings containing printed silica on the board surface. The bleeding properties have been measured from these kinds of printed patterns. Figure 10 shows the results of the bleeding of magenta line on the plain paper surface (spreading) or beside the yellow printed surface (intercolor bleeding). The widest and the most ragged printed line formed on the surface of the coating containing colloidal silica. Again, the low porosity of the coating containing colloidal silica prevented the quick penetration of inkjet ink. The coatings containing $\mathrm{CaCO}_{3}$ provide a more packed coating layer structure.

The coatings containing precipitated and produced silica brought in the lowest bleeding results. Papers coated with these coatings had high air permeance, a high pene-

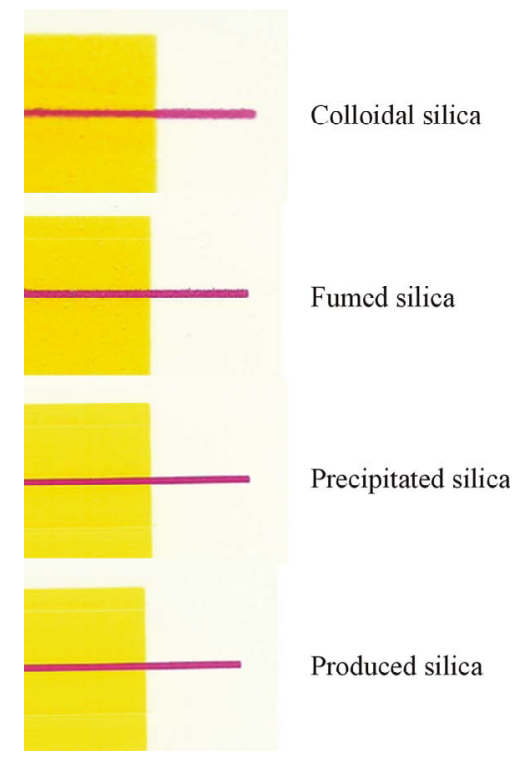

Figure 9. The printed images of coatings containing colloidal, precipitated and fumed silica on the board surface.

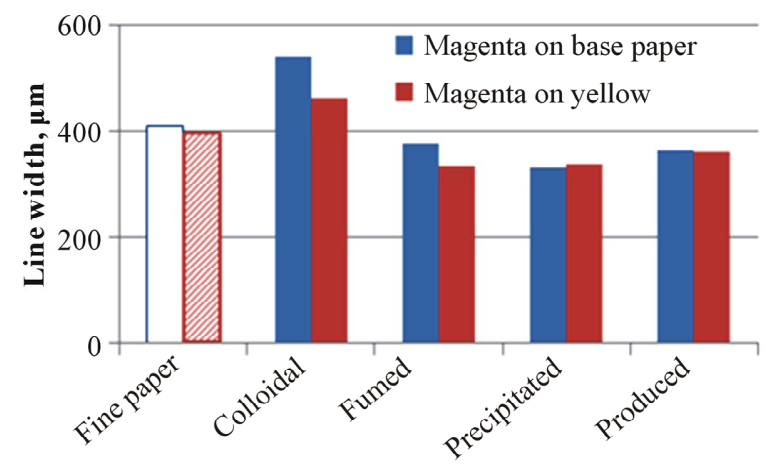

(a)

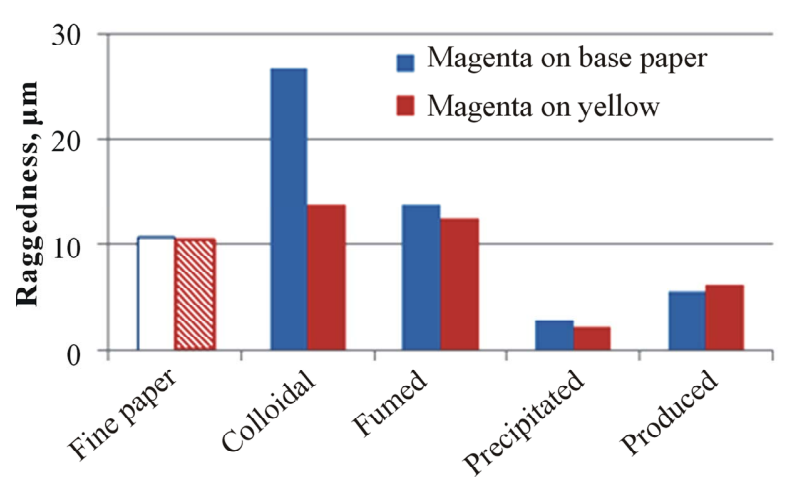

(b)

Figure 10. The bleeding (line width (a) and raggedness (b)) of printed uncoated and silica-pigment-coated surfaces. The area had $100 \%$ halftone dot. The printing was made with an HP Deskjet 2050 printer that had dye-based magenta and yellow ink.

trated inkjet ink amount at $8 \mathrm{~ms}$ and could absorb the dye-based inkjet ink quickly into the structure, indicating a coating structure of high porosity. 
Besides the spreading of printed lines and intercolor bleeding, we can look at the bleeding tendency of surfaces by studying the outlook of printed letters. The coating containing colloidal silica again had the most spread letters, as Figure 11 shows. The coating containing fumed silica had a clearly better letter quality than that containing colloidal silica. The more porous structure of the fumed silica coating provided for quicker penetration of inkjet ink into the surface, and therefore, the ink could not spread so much on the surface. The coating containing produced silica had a poorer letter quality than that containing precipitated silica. These results supported the view that nitric-acid-based silica pigment production requires further development work.

We expected at first that the cationic ionic charge of the coating structure should bind the anionic dye colorant effectively by Coulombic forces to the top layer of the coating structure, and therefore, the print density should become high and the bleeding would be minimal. However, with the coating containing cationic fumed silica the print density and bleeding of anionic dye-based inks remained at the same level as the other silicas. This shows that the cationic ionic charges of the coating layer are not available for dye molecules during the inkjet ink setting. The result is very similar to that noticed by Svanholm et al. [15] in their study. We suggest that the polyvinyl alcohol has covered or partially covered the pigment surfaces, and the cationic ionic charges are located under the binder polymer. If the specific surface area of coating pigment is low, the binder (PVOH) can cover the pigment surface with a thick layer, and the ionic charge of the coating layer remains, at least partially, under the binder layer (Figure 12). The attraction between the cationic ionic charges on the coating pigment surface and the anionic colorant of ink has therefore been prevented. In this case, the colorant molecules follow the diffused inkjet ink vehicle (mainly water) into the binder polymer matrix [25]. Figure 13 shows how commercial anionic dye-based cyan inkjet ink has transferred in the partially hydrolyzed PVOH film structure,

\begin{tabular}{|c|c|}
\hline C:Ukuvat mmmagen $2 . \mathrm{hmp}$ & Uncoated board \\
\hline C:lkuvatimnumagen2.bup & Colloidal nanosilice \\
\hline C:Lkuvat'mmmagen2.bmp & Fumed nanosilica \\
\hline C:kuvat \mmmagen2.bmp & Precipitated silica \\
\hline C:Luvatımmmagen2.bmp & Produced silica \\
\hline
\end{tabular}

Figure 11. The printed texts of uncoated board and coated boards containing silica pigment.

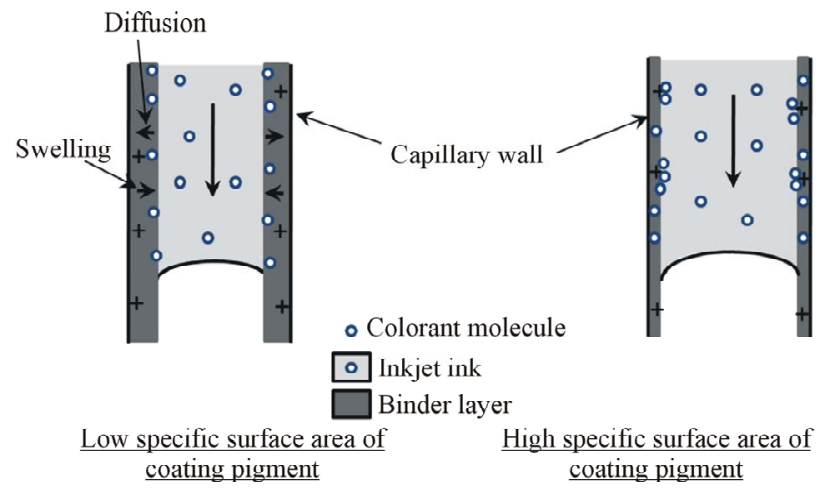

Figure 12. The role of the ionic charge of coating surface on dye-based colorant (anionic) transfer.

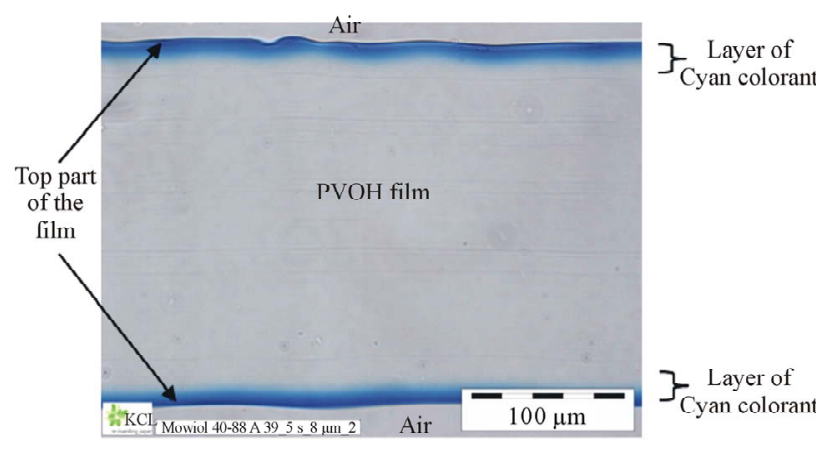

Figure 13. Cross-section figure of polyvinyl alcohol film that had been immersed for $5 \mathrm{~s}$ in commercial anionic dye-based inkjet ink. Imaged by light microscopy (Zeiss Axioskope 2 plus).

forming chromatographic separation of ink colorant molecules. The top surface of the film has a deeper cyan color than the inner part of the colorant layer.

In the case of high specific surface area pigment, as in the coating containing precipitated silica pigment (Table 3), and at constant binder content, binder can form only a thin layer on the top of pigment surface, and therefore, the cationic ionic charges of the coating layer could play a more important role in colorant attraction than in the case of thick binder layer. In Table 3, we have made a rough estimation of the connection between the specific surface area of the studied silica particles and the forming binder layer thickness on the pigment particle surfaces. However, in this study, the silica coatings other than coatings containing fumed silica had anionic ionic charge, and in theory an electrostatic repulsion should therefore appear between the anionic pigment surface and anionic dye molecules. The studied anionic coatings provided very similar print densities to the coating layer containing cationic fumed silica. It seems that in the anionic coating systems the diffusion of hydrophilic binder still has a dominant role in colorant attachment. Thus in the case of hydrophilic binder and coatings containing low specific surface area pigment, the attachment of the 
Table 3. The calculated specific surface area of the coating colors studied. The pigment content of recipes and the specific surface area of each pigment have been taken into account in the calculations. In the approximation of $\mathrm{PVOH}$ thickness, the amount of PVOH was 25 pph and the specific gravity of PVOH $1.26 \mathrm{~g} \cdot \mathrm{cm}^{-3}$. It was also assumed that PVOH covered the top of pigment surfaces with a uniform binder layer. (In a real coating layer, the binder amount has variation).

\begin{tabular}{ccccc}
\hline & $\begin{array}{c}\text { Colloidal } \\
\text { nanosilica }\end{array}$ & $\begin{array}{c}\text { Fumed } \\
\text { nanosilica }\end{array}$ & \multicolumn{2}{c}{ Precipitated Produced } \\
silica & silica \\
\hline $\begin{array}{c}\text { Calculated specific } \\
\text { surface area, } \mathrm{m}^{2} \cdot \mathrm{g}^{-1}\end{array}$ & 66.4 & 138 & 634 & 162 \\
$\begin{array}{c}\text { Approximated } \mathrm{PVOH} \\
\text { film thickness on the } \\
\text { pigment surface, } \mathrm{nm}\end{array}$ & 2.41 & 1.15 & 0.25 & 0.98 \\
\hline
\end{tabular}

dye molecules of inkjet ink is dominated by the competition between diffusion and electrostatic interactions during the ink penetration into the pores of the coating layer through capillary and permeation flow.

\section{Conclusions}

Silica pigments have very commonly been used in inkjet coatings because they generate a coating structure with high porosity. Also, the capillary structure of silica pigment coatings promotes a quick inkjet ink penetration, and the inkjet ink transfers mainly in the $\mathrm{z}$ direction of the coating layer. One disadvantage of silica pigment is its high cost. By producing the silica from low-cost raw materials, such as mine tailings, the cost could be reduced. In this work, the silica pigment was manufactured from olivine rock using nitric acid. The properties of produced silica were compared to commercial silicas. In some coating colors, $20 \mathrm{pph}$ of silica was replaced with calcium carbonate pigment to investigate the possibility of decreasing the costs of coating colors through less expensive pigment addition.

The results show that it is possible to produce silica pigments from olivine rock, and that the pigment has potential in the area of matt quality coated inkjet papers, as well as in inkjet printable white-top kraftliner board. The coatings containing produced silica provide very similar print density, print-through, print gloss and bleeding results to the coatings containing commercial precipitated silica. However, the silica pigment production and the coating color formulation require further development work, for example in the area of particle size and purity. The results of the coatings that contained $20 \mathrm{pph}$ of less expensive calcium carbonate with silica pigment show that it is possible with these coating layers to gain quite similar print densities to those with coating containing only precipitated silica. However, the low porosity of these coatings causes some higher bleeding tendency, and this limits the wider use of normal low spe- cific surface area pigment in the coatings for inkjet printing. The olivine-based silica pigments are suitable for inkjet coatings, but manufacture of the pigment needs further development work.

\section{Acknowledgements}

The work has received funding from the European Community's Seventh Framework Programme. Thanks are due to Unto Tapper for measuring the SEM images.

\section{REFERENCES}

[1] R. Gong and P. D. Fleming, "Application of Nano Pigments in Inkjet Paper Coating," NIP26 International Conference of Digital Printing Technologies, Austin, 1923 September 2010, pp. 507-511.

[2] L. Shaw-Klein, A. Wexler, D. Giacherio and L. Demejo, "Materials for High-Quality Inkjet Papers," PTS 23rd Coating Symposium, Baden-Baden, 18-21 September 2007, 8 Pages.

[3] E. Svanholm, "Printability and Ink-Coating Interactions in Inkjet Printing," Doctoral Thesis, Karlstad University, Faculty of Technology and Science, Chemical Engineering, Karlstad, 2007.

[4] K. Vikman and T. Vuorinen, "Water Fastness of Ink Jet Prints on Modified Conventional Coatings," Journal of Imaging Science and Technology, Vol. 48, No. 2, 2004, pp. 138-147.

[5] H.-K. Lee, M. K. Joyce, P. D. Fleming and J. H. Cameron, "Production of a Single Coated Glossy Inkjet Paper Using Conventional Coating and Calendering Methods," Tappi Coating and Graphic Arts Conference and Trade Fair, Orlando, 5-8 May 2002, 24 Pages.

[6] D. W. Donigian, P. C. Wernett, M. G. McFadden and J. J. McKay, "Ink jet Dye Fixation and Coating Pigments," Proceedings Tappi Coating/Papermakers Conference, New Orleans, 4-6 May 1998, pp. 393-412.

[7] M. P. Wild and K. R. Andersson, "A Novel Coating Formulation for Silica Inkjet Layer Coatings," NIP24 International Conference of Digital Printing Technologies, Pittsburgh, 6-11 September 2008, pp. 383-386.

[8] D. Glittenberg, A. Voigt and D. Donigian, "Novel Pigment-Starch Combination for the Online and Offline Coating of High-quality Inkjet Papers," Paper Technology, Vol. 44, No. 7, 2003, pp. 36-42.

[9] K. Kumaki and S. Nii, "Polyvinyl Alcohol in Ink Jet Coatings," Tappi PaperCon, Atlanta, 2-5 May 2010, 27 Pages.

[10] T. T. Lamminmäki, J. P. Kettle, P. J. T. Puukko and P. A. C. Gane, "Absorption Capability and Inkjet Ink Colorant Penetration into Binders Commonly Used in Pigmented Paper Coatings," Industrial and Engineering Chemistry Research, Vol. 50, No. 6, 2011, pp. 3287-3294. doi:10.1021/ie102178x

[11] K. Hara, "Specialty PVOH in Ink Jet Coating Formulations," Paper Technology, Vol. 47, No. 3, 2006, pp. 27 30 . 
[12] P. B. Malla and S. Devisetti, "Novel Kaolin Pigment for High Solids Ink Jet Coating," Paper Technology, Vol. 46, No. 8, 2005, pp. 17-27.

[13] A. Swerin, A. König and B. Brandner, "The Use of Silica Pigments in Coated Media for Inkjet Printing: Effects of Absorption and Porosity on Printing Performance and Depth-Profiling Using Confocal Raman Spectroscopy," TAPPI 10th Advanced Coating Fundamentals Symposium, Montreal, 11-13 June 2008, 27 Pages.

[14] M. Ettlinger, T. Ladwig and A. Weise, "Surface Modified Fumed Silicas for Modern Coatings," Progress Organic Coatings, Vol. 40, No. 1-4, 2000, pp. 31-34. doi:10.1016/S0300-9440(00)00151-X

[15] E. Svanholm and G. Gtröm, "Influence of Polyvinyl Alcohol on Inkjet Printability," International Printing and Graphic Arts Conference, Vancouver, 4-6 October 2004, pp. 187-198.

[16] N. V. Krupkin, B. C. Stief, M. R. Sestrick and D. Michos, "Silica Nanoparticles: Design Considerations for Transparent and Glossy Inkjet Coatings," NIP 21 International Conference of Digital Printing Technologies, Baltimore, 18-23 September 2005, pp. 442-444.

[17] D. A. Young, N. L. Bowen and H. H. Hess, "Perspectives on Phiolites before Plate Tectonics. Ophiolite Concept and the Evolution of Geological Thought," In: Y. Dilek and S. Newcomb, Eds., Special Paper 373, The Geological Society of America, Boulder, 2003, 59 Pages.

[18] Olivine, "The Mineral Olivin," 2013. http://www.galleries.com/Olivine

[19] E. Kenttä, T. Lamminmäki, H. Rautkoski, J. Bacher, S. Teir, J. Kettle and J. Sarlin, "Silica Pigment Produced from Silicate Mining Sidestreams for Ink-Jet Paper Coating Application," Nordic Pulp Paper Research Journal, Vol. 28, No. 1, 2013, pp. 22-27. doi:10.3183/NPPRJ-2013-28-01-p022-027

[20] Mowiol Polyvinyl Alcohol. Procure of the Chemical, Clariant, 1999.

[21] T. Lamminmäki and P. Puukko, "New Ink Absorption Method to Predict Inkjet Print Quality, Advances in Printing and Media Technology," 34th International Research Conference of Iarigai, Grenoble, 9-12 September 2007, pp. 231-239.

[22] A. Bristow, "Liquid Absorption into Paper during Short Time Intervals," Svensk Papperstidning, Vol. 77, No. 19, 1967, pp. 623-629.

[23] F. Tiberg, B. Zhmud, K. Hallestensson and M. von Bahr, "Capillary Rise of Surfactant Solutions," Physical Chemistry Chemical Physics, Vol. 2, No. 22, 2000, pp. 51895196. doi:10.1039/b004458j

[24] G. M. Laudone, G. P. Matthews and P. A. C. Gane, "Coating Shrinkage during Evaporation: Observation, Measurement and Modelling within a Network Structure," Tappi 8th Advanced Coating Fundamentals Symposium, Chicago, 8-10 May 2003, pp. 116-129.

[25] T. Lamminmäki, J. Kettle, P. Puukko and P. Gane, "Absorption and Adsorption of Dye-Based Inkjet Inks by Coating Layer Components and the Implications for Print Quality," Colloids and Surface A: Physicochemical and Engineering Aspects, Vol. 380, No. 1-3, 2011, pp. 79-88. doi:10.1016/j.colsurfa.2011.02.015 